\title{
Twin Heritability Study of the Effect of Corticosteroids on Intraocular Pressure
}

\author{
J. T. SCHWARTZ, F. H. REULING, M. FEINLEIB, R. J. GARRISON, and \\ D. J. COLLIE
}

\section{From the Section on Ophthalmic Field and Developmental Research, Office of Biometry and Epidemiology, National Eye Institute, Bethesda, Maryland and the Epidemiology Branch, National Heart and Lung Institute, Bethesda, Maryland, USA}

A glaucoma-like rise in intraocular pressure following prolonged use of cortisone was documented by François in 1954 . Since then, the influence of glucocorticosteroid (steroid) eye drops on intraocular pressure has been studied extensively. Provocative testing of healthy eyes with topical steroid preparations has led to the characterization of a 'steroid response' consisting of a gradual rise in intraocular pressure when medication is instilled several times daily over a period of 4 to 6 weeks. When the topical steroid is discontinued the intraocular pressure returns to normal levels.

Among groups of randomly selected subjects, steroid provocative testing evokes a heterogeneous response. Some subjects show a temporary glaucoma-like elevation of intraocular pressure, while others show little or no response. Frequency distributions of change in ocular pressure or of final pressure following a course of steroid provocation show a skew tailing towards the high end. On the basis of multimodal characteristics reported for sample frequency distributions, some investigators (Armaly, 1965; Armaly and Becker, 1965; Becker, 1971) have distinguished 3 subpopulations characterized by low, intermediate, and high levels of pressure response. An hypothesis has been advanced, based on population testing and family studies, that the hypertensive response to steroids is determined genetically by a simple autosomal mechanism (Armaly, 1966; Becker and Kolker, 1966; Becker, 1969). It is postulated that 3 distinct phenotypes can be identified by the level of pressure response and that these phenotypes correspond to the 3 possible genotypes of an allele pair, wherein one member of the pair determines a high level of response and the other member a low level of response. This genetic hypothesis holds pro-

Received 25 January 1972. minent interest in the field of ophthalmology as it is also postulated that the 3 phenotypes represent prospective primary open-angle glaucoma cases, glaucoma carriers, and normal noncarriers (Becker and Kolker, 1966; Becker and Hahn, 1964). More recently, steroid responsiveness has been related to phenylthiourea taste testing (Becker, 1969), diabetes mellitus (Becker et al, 1966; Armaly, 1967), thyroid function (Becker and Kolker, 1969), and myopia (Podos, Becker, and Morton, 1966).

Becker (1967 and 1971) and Armaly (1965 and 1966) are the main proponents of a genetic explanation for the heterogeneous steroid response. Mention of selected findings from the work of these investigators will be helpful in defining the purpose and approach of the present study.

Working independently, each investigator selected a different parameter of intraocular pressure response to characterize phenotypic reaction to topical steroid. Armaly separated 3 levels of responsiveness on the basis of change in pressure in the treated eye while Becker used the criterion of final pressure in the treated eye. Table I gives the specific criteria used by Armaly (1965) and Becker (1965) to classify phenotypes and shows the percentage of normal volunteer subjects tabulated according to the parameter adopted by each author. Frequency distributions of change in pressure and final pressure were interpreted by Armaly and Becker to demonstrate appropriate discontinuity at the levels of phenotypic demarcation which are shown.* The proportions of subjects classified by each investigator as low, intermediate, and high responders are in close agreement.

Family studies were undertaken by Armaly and

* To define the demarcation between medium and high responders Becker employed, in addition to the data cited in Table I, observations made on patients with primary open-angle glaucoma, their relatives, and glaucoma suspects. 
TABLE I

\begin{tabular}{|c|c|c|c|c|c|c|c|}
\hline \multirow{3}{*}{ Author } & \multirow{3}{*}{ Parameter of Response } & \multirow{3}{*}{$\begin{array}{l}\text { No. of } \\
\text { Subjects }\end{array}$} & \multicolumn{5}{|c|}{ Distribution of Steroid Response } \\
\hline & & & \multirow{2}{*}{ Mean (mm Hg) } & \multirow{2}{*}{$\mathrm{SD}(\mathrm{mm} \mathrm{Hg})$} & \multicolumn{3}{|c|}{ Phenotype (and hypothetical genotype) } \\
\hline & & & & & Low & Medium & High \\
\hline \multirow[t]{2}{*}{$\begin{array}{c}\text { Armaly } \\
(1965)\end{array}$} & $\begin{array}{l}\text { Change in pressure in } \\
\text { eye medicated } 4 \text { weeks } \\
\text { with } 0 \cdot 11^{\circ}\end{array}$ & 80 & $5 \cdot 5^{*}$ & $\pm 4 \cdot 0^{*}$ & $\leq 5 \underset{\left(\mathbf{P L P}^{L}\right)}{\operatorname{mg}} \mathrm{Hg}$ & $\underset{\left(\mathrm{P}^{\mathrm{L}} \mathrm{P}^{\mathrm{H}}\right)}{6-15} \mathrm{mg}$ & $\geq \underset{\left(\mathrm{P}^{\mathrm{H}} \mathrm{P}^{\mathrm{H}}\right)}{16 \operatorname{mm}} \mathrm{Hg}$ \\
\hline & & & & & $66^{\circ}$ o & $29^{\circ} \circ$ & $5^{\circ}$ \\
\hline \multirow[t]{2}{*}{$\begin{array}{l}\text { Becker } \\
(1965)\end{array}$} & $\begin{array}{l}\text { Final pressure in eye } \\
\text { medicated } 6 \text { weeks with } \\
0 \cdot 1^{\circ} \text { o betamethasone }\end{array}$ & 50 & $17 \cdot 0$ & $\pm 3 \cdot 0$ & $\leq \underset{(\mathrm{nn})}{19 \underset{\mathrm{mm}}{\mathrm{Hg}}}$ & $\underset{(\mathrm{ng})}{20-31 \mathrm{~mm}} \mathrm{Hg}$ & 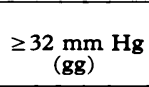 \\
\hline & & & & & $70^{\circ}$ o & $26^{\circ}$ o & $4^{\circ}$. \\
\hline
\end{tabular}

* Values derived from published data.

Becker with genotypes assigned as shown in Table I. Although there are minor differences in allelic nomenclature, the single gene models for each parameter of steroid responsiveness were similar. Observed offspring segregation data, reproduced in Table II conformed closely to the ratios expected for monogenic inheritance (Armaly, 1966; Becker and Kolker, 1966).

Theoretical objections to the monogenic hypothesis have been raised (François, Heintz-De Bree, and Tripathi, 1966; B. Schwartz, 1966; Levene et al, 1967; Spaeth, 1966 and 1967) and data have been presented which are in conflict with some of the observations of Becker and Armaly (François et al, 1966; Spaeth, 1966 and 1967). Because of the importance of this theory to the field of ophthalmology and its emerging importance to related fields, the present twin study was undertaken to reassess the influence of genetic factors. If the trait is inherited, measures of steroid responsiveness would be expected to show greater intrapair variation among dizygotic twins than among monozygotic twins. If wholly inherited, very little intrapair variation is expected among the monozygotic pairs.

\section{Method}

General descriptions of the study protocol and the local twin register from which participants were drawn were presented at the First International Symposium on Twin Studies (Reuling and J. T. Schwartz, 1970; J. T. Schwartz, 1970). Subjects were monozygotic (MZ) and like-sex dizygotic (DZ) twins with essentially normal eye examinations. All had volunteered after being fully apprised of the rigorous schedule of eye drops and return visits. Zygosity was determined on the basis of blood serotyping including $\mathrm{ABO}, \mathrm{MN}, \mathrm{SsU}, \mathrm{P}, \mathrm{Rh}$, Kell, Lewis, Duffy, Kidd, Diego, and haptoglobin type.

Each twin was placed on a regimen of $0.1 \%$ dexamethasone* ophthalmic drops to the right eye 3 times daily for 4 weeks. Each was provided with a pocket calendar to record times drops were taken, and, of equal importance, to enter a note of any drops missed.

Participation in the study required approximately 7

* $0.1 \%$ dexamethasone phosphate equivalent, Decadron (Merck, Sharp, and Dohme).

TABLE II

\begin{tabular}{|c|c|c|c|c|c|c|}
\hline \multirow[t]{2}{*}{$\begin{array}{l}\text { Author and Parameter } \\
\text { of Response }\end{array}$} & \multirow{2}{*}{$\begin{array}{l}\text { Hypothetical } \\
\text { Phenotype of } \\
\text { Parents }\end{array}$} & \multirow[t]{2}{*}{ No. of Families } & \multirow[t]{2}{*}{ No. of Subjects } & \multicolumn{3}{|c|}{$\begin{array}{c}\text { Observed Distribution of Hypothetical } \\
\text { Phenotypes and Genotypes among Offspring }\end{array}$} \\
\hline & & & & Low & Medium & High \\
\hline \multirow[b]{2}{*}{$\begin{array}{l}\text { Armaly (1966): } \\
\text { Change in pressure }\end{array}$} & \multirow[b]{2}{*}{$\begin{array}{l}(\mathbf{P L P L}) \times\left(\mathbf{P L P L}^{\mathbf{L L}}\right) \\
\left(\mathbf{P L P H}^{\mathbf{L}}\right) \times\left(\mathbf{P H P H}^{\mathrm{H}}\right) \\
\left(\mathbf{P L}^{\mathrm{L}}\right) \times\left(\mathbf{P}^{\mathrm{L}} \mathbf{P H}^{\mathrm{H}}\right) \\
\end{array}$} & & & $\leq \underset{\left(P^{L} \mathrm{Pm}^{\mathrm{L}}\right)}{5 \mathrm{mg}}$ & $\underset{\left(\mathbf{P}^{\mathbf{L}} \mathbf{P}^{\mathrm{H}}\right)}{6-15 \mathrm{~mm}_{\mathrm{H}} \mathrm{Hg}}$ & $\geq \underset{\left(\mathbf{P}^{\mathrm{H}} \mathbf{P H}^{\mathrm{H}}\right)}{16 \mathrm{mg}}$ \\
\hline & & $\begin{array}{l}7 \\
3 \\
4 \\
\end{array}$ & $\begin{array}{l}41 \\
15 \\
19 \\
\end{array}$ & $\begin{aligned} & 98^{\circ}{ }^{\circ} \\
& 0^{\circ}{ }^{\circ} \\
& 26^{\circ} \\
&\end{aligned}$ & $\begin{aligned} 2 \% \\
47 \% \\
53 \% \\
\end{aligned}$ & $\begin{aligned} & 0^{\circ} \\
& 53 \circ^{\circ} \\
& 210^{\circ} \\
&\end{aligned}$ \\
\hline \multirow{2}{*}{$\begin{array}{l}\text { Becker and Kolker (1966): } \\
\text { Final pressure }\end{array}$} & \multirow[b]{2}{*}{$\begin{array}{l}(\mathbf{n n}) \times(\mathbf{n n}) \\
(\mathbf{n n}) \times(\mathbf{n g}) \\
(\mathbf{n g}) \times(\mathbf{n g}) \\
(\mathbf{g g}) \times(\mathbf{g g})\end{array}$} & & \multirow[b]{2}{*}{$\begin{array}{l}21 \\
42 \\
25 \\
12\end{array}$} & $\leq \underset{(\mathrm{nn})}{19 \mathrm{~mm} \mathrm{Hg}}$ & $\begin{array}{c}20-31 \mathrm{~mm} \\
(\mathrm{ng})\end{array}$ & $\underset{(\mathrm{gg})}{\geq 32 \mathrm{~mm}} \mathrm{Hg}$ \\
\hline & & & & $\begin{array}{r}95^{\circ} \\
48^{\circ} \\
20^{\circ} \\
0^{\circ} \circ\end{array}$ & $\begin{aligned} 55^{\circ} \\
52^{\circ} \\
56^{\circ} \\
0^{\circ}\end{aligned}$ & $\begin{array}{r}0^{\circ} \% \\
0^{\circ} \% \\
24^{\circ} \% \\
100^{\circ} \%\end{array}$ \\
\hline
\end{tabular}


TABLE III

STUDY POPULATION ZYGOSITY; AGE AND SEX IN 63 TWIN PAIRS

\begin{tabular}{|c|c|c|c|c|c|c|}
\hline \multirow{2}{*}{ Age (yr) } & \multicolumn{3}{|c|}{ Monozygotic } & \multicolumn{3}{|c|}{ Like Sex Dizygotic } \\
\hline & Male & Female & No. of Males and Females & Males & Females & No. of Males and Females \\
\hline $15-24$ & 8 & 12 & $20(54 \%)$ & 11 & 6 & $17(65 \%)$ \\
\hline $25-34$ & 0 & 3 & $3(8 \%)$ & 1 & 2 & $3(12 \%)$ \\
\hline $35-44$ & 3 & 2 & $5\left(14_{0}^{\circ}\right)$ & 1 & 1 & $2\left(8_{0}^{\circ}\right)$ \\
\hline \multirow[t]{2}{*}{$45+$} & 2 & 7 & $9(24 \%)$ & 1 & 3 & $4(15 \%)$ \\
\hline & 13 & 24 & $37(2) *(100 \%)$ & 14 & 12 & $26(5) *(100 \%)$ \\
\hline
\end{tabular}

* Nonwhite.

clinic visits for which a total compensation of $\$ 50.00$ was provided. It was known to the subjects that compensation did not depend on their performance in adhering to the medication schedule. Rather, the importance of a true medication tally was stressed.

The data to be presented were obtained from measures of intraocular pressure in the treated right eye taken just before the medication schedule and again at the end of 4 weeks. Pressure measurements were taken by two of us (F.H.R. and D.J.C.), using the Goldmann applanation tonometer and were recorded in whole millimeters of mercury.

\section{Results}

Eighty pairs of twins, $49 \mathrm{MZ}$ and $31 \mathrm{DZ}$, entered the study. Seventeen pairs were subsequently excluded. One or both members of these 17 twinships failed to adhere to the protocol or reported missing more than 10 drops of the full 84 drop schedule. Pairs were excluded without regard to zygosity or pressure. The present report pertains to the remaining 63 pairs, all of whom adhered closely to the protocol.

As shown in Table III, the $\mathrm{MZ}$ and $\mathrm{DZ}$ populations were in reasonable balance for age. Average initial intraocular pressure was nearly identical for the $\mathrm{MZ}$ and $\mathrm{DZ}$ populations, being 13.9 and 14.0 $\mathrm{mm} \mathrm{Hg}$ respectively. Comparison of steroid response showed no significant differences on the basis of age, race, or sex, and therefore, the data for these subgroups were combined. Likewise the response among individuals did not differ by zygosity. Table IV gives the proportions of responders for the total study population, tabulated according to previously described criteria of pressure response. The proportion of subjects showing a response graded as medium or above in this table is somewhat greater than reported by either Armaly or Becker. It is concluded that the potency of the steroid regimen as followed by the volunteer twin population is as great or greater than observed among the referenced study populations.

The shapes of the frequency distributions for final pressure and change in pressure were examined. The distribution of change in pressure showed a skew tailing toward the high end without evidence of discontinuity. An apparent discontinuity did occur in the distribution of final pressure but, contrary to expectations, a trough was located toward the centre of the range for intermediate responsiveness. This is where peak frequency ought to occur for the postulated phenotype representing heterozygosity. Because of the relatively small number of subjects, little importance is presently attached to the observed discontinuity for final pressure.

Five of the 126 individuals included in Table IV experienced a pressure rise into the highest level before completing 4 full weeks of medication.

TABLE IV

INTRAOCULAR PRESSURE RESPONSE TO 4-WEEK $0 \cdot 1 \%$ DEXAMETHASONE IN 63 TWIN PAIRS

\begin{tabular}{|c|c|c|c|c|c|c|}
\hline \multirow{2}{*}{ Parameter of Response } & \multirow{2}{*}{ No. of Subjects } & \multicolumn{5}{|c|}{ Distribution of Response } \\
\hline & & $\operatorname{Mean}(\mathrm{mm} \mathrm{Hg})$ & $\mathrm{SD}(\mathrm{mm} \mathrm{Hg})$ & Low & Medium & High \\
\hline \multirow{2}{*}{ Change in pressure in medicated eye } & \multirow{2}{*}{126} & \multirow{2}{*}{$5 \cdot 6$} & \multirow{2}{*}{$4 \cdot 7$} & $\leq 5 \mathrm{~mm} \mathrm{Hg}$ & 6-15 $\mathrm{mm} \mathrm{Hg}$ & $\geq 16 \mathrm{~mm} \mathrm{Hg}$ \\
\hline & & & & $78(62 \%)$ & $42(33 \%)$ & $6(5 \%)$ \\
\hline \multirow{2}{*}{ Final pressure in medicated eye } & \multirow{2}{*}{126} & \multirow{2}{*}{$19 \cdot 5$} & \multirow{2}{*}{$5 \cdot 5$} & $\leq 19 \mathrm{~mm} \mathrm{Hg}$ & $20-31 \mathrm{~mm} \mathrm{Hg}$ & $\geq 32 \mathrm{~mm} \mathrm{Hg}$ \\
\hline & & & & $69(55 \%)$ & $51(40 \%)$ & $6(5 \%)$ \\
\hline
\end{tabular}


When this occurred, the medication of all 5 of them was stopped as a precautionary measure. Had the medication been continued, average pressure response might tend to be greater than shown in Table IV. With regard to observations on the contour of the skewed frequency distributions, the possible mid-zone discontinuity noted in the distribution of final pressure is not affected.

To assess the role of genetic factors in determining the steroid response, values of the heritability index (HI) were calculated by 2 methods, treating the response as both a qualitative trait or discontinuous variable and as a quantitative trait or continuous variable. For calculation as a qualitative trait, the method of Holzinger (1929) was used, based on percent concordance among the $M Z$ and DZ populations. The heritability index for both change in pressure and final pressure are given in Table V. Qualitative response was assigned according to the postulated phenotypes. In the upper row of the table, calculations were based on concordance for any of the 3 postulated phenotypes. In the lower row, medium and high responsiveness were combined into a single category in order to group the population into 'responders' and 'nonresponders'. Values of HI were relatively low by all qualitative methods of calculation. None of the differences in concordance rates for the $M Z$ and $\mathrm{DZ}$ populations were statistically significant by the chi-square test for differences in proportions.

To calculate HI treating steroid response as a quantitative trait, a method based on intrapair variance among the $M Z$ and $D Z$ populations was used (Penrose, 1949; Clark, 1956). As stated earlier, 5 subjects had their medication terminated before 4 full weeks had passed. Four twin pairs were involved. In 3 sets- $2 \mathrm{MZ}$ and one $\mathrm{DZ}-$ one of the members exhibited a high response at the end of 3 weeks and was terminated, while each co-twin received 4 full weeks of medication. Additionally, in one $M Z$ set, both twins showed high pressure rise at the end of the 2nd week at which time medication for both was terminated. These 5 subjects comprise the earliest high responders and provide important input for data analysis. There is, however, no 'best' way of handling their data. Accordingly, in the quantitative analysis, these pertinent data were treated several ways. The results are given in Table VI.

In row 1 of Table VI, intrapair differences for the terminated pairs were calculated using the final pressure value available for each subject while under medication. In row 2, intrapair differences were calculated using truncated data representing the final measurements which were paired in time, ie, for 3 sets, the 3 rd-week values were used, and for one set 2nd-week values were used. In row 3, the calculation was similar to that of row 2 except that a zero value was assigned as the intrapair difference for the $M Z$ pair wherein both members exhibited a high rise at 2 weeks. Insofar as both members of this $M Z$ twinship exhibited an early high response, it seems reasonable to attempt to increase the estimate of heritability by assuming complete agreement for the pair. In row 4, the data for each of the 4 twin sets were selected so as to maximize the calculation of HI. A zero value was again assigned as the intrapair difference for the $M Z$ co-twins showing high response at 2 weeks. Those individuals who had their medication terminated at 3 weeks would have been expected to show a further rise in pressure by the end of week 4 , ie, a further

TABLE V

HERITABILITY INDICES (HI) FOR CHANGE IN PRESSURE AND FINAL PRESSURE WITH 0.1\% DEXAMETHASONE-INDUCED OCULAR HYPERTENSION: PRESSURE RESPONSE AS A QUALITATIVE TRAIT IN 63 TWIN PAIRS (37 MONOZYGOTIC [MZ] AND 26 DIZYGOTIC [DZ])

\begin{tabular}{|c|c|c|c|c|c|c|}
\hline \multirow{4}{*}{ Criteria for Concordance } & \multicolumn{6}{|c|}{ Parameter of Response } \\
\hline & \multicolumn{3}{|c|}{ Change in Pressure } & \multicolumn{3}{|c|}{ Final Pressure } \\
\hline & \multicolumn{2}{|c|}{$\%$ Concordant } & \multirow{2}{*}{$\mathrm{HI}^{*}$} & \multicolumn{2}{|c|}{$\%$ Concordant } & \multirow{2}{*}{$\mathrm{HI}^{*}$} \\
\hline & $\mathbf{M Z}$ & DZ & & $M Z$ & $\mathrm{DZ}$ & \\
\hline $\begin{array}{r}3 \text { Levels of response } \\
\text { Concordance }=\mathrm{L}-\mathrm{L} \\
\mathrm{M}-\mathbf{M} \\
\mathrm{H}-\mathrm{H}\end{array}$ & 62 & 54 & 0.17 & 65 & 46 & 0.35 \\
\hline $\begin{array}{l}2 \text { Levels of response } \\
\text { Concordance }=\mathbf{L}-\mathbf{L} \\
(\mathbf{M} \text { or } \mathbf{H})-(\mathbf{M} \text { or } \mathbf{H})\end{array}$ & 68 & 54 & $0 \cdot 31$ & 71 & 54 & $0 \cdot 37$ \\
\hline
\end{tabular}


TABLE VI

HERITABILITY INDEX (HI) FOR CHANGE IN PRESSURE AND FINAL PRESSURE WITH $0.1 \%$ DEXAMETHASONE-INDUCED OCULAR HYPERTENSION: PRESSURE RESPONSE AS A QUANTITATIVE TRAIT IN 63 TWIN PAIRS

\begin{tabular}{|c|c|c|c|c|c|c|}
\hline \multirow{3}{*}{$\begin{array}{l}\text { Methods of Dealing with Subjects } \\
\text { on Terminated Medication (see text) }\end{array}$} & \multicolumn{3}{|c|}{ Change in Pressure } & \multicolumn{3}{|c|}{ Final Pressure } \\
\hline & \multicolumn{2}{|c|}{ Intrapair Variance } & \multirow{2}{*}{$\mathrm{HI}^{*}$} & \multicolumn{2}{|c|}{ Intrapair Variance } & \multirow{2}{*}{$\mathrm{HI}$} \\
\hline & $\mathbf{M Z}$ & DZ & & $M Z$ & $\mathrm{DZ}$ & \\
\hline 1. Final individual pressures & 9.91 & $8 \cdot 81$ & $-0 \cdot 12$ & $9 \cdot 31$ & $14 \cdot 23$ & 0.35 \\
\hline 2. Final time-paired pressures & $10 \cdot 43$ & $9 \cdot 33$ & $-0 \cdot 12$ & $10 \cdot 32$ & $14 \cdot 87$ & 0.31 \\
\hline $\begin{array}{l}\text { 3. Final time-paired pressures } \\
\text { (modified) }\end{array}$ & 9.95 & $9 \cdot 33$ & -0.07 & $9 \cdot 46$ & $14 \cdot 87$ & 0.36 \\
\hline 4. Maximum calculated HI & $9 \cdot 42$ & $9 \cdot 33$ & -0.01 & $8 \cdot 45$ & $14 \cdot 87$ & 0.43 \\
\hline
\end{tabular}

$* \mathrm{HI}=1-\sigma^{2} \mathrm{MZ} / \sigma^{2} \mathrm{DZ}$.

increase in co-twin disparity had their medication been continued. Accordingly, for the $2 \mathrm{MZ}$ pairs where medication for one member was terminated at 3 weeks, the data were treated as in row 1 to minimize the intrapair difference. Conversely, for the single $\mathrm{DZ}$ pair the data were treated as in row 2.

Estimates of $\mathrm{HI}$ were relatively low by all methods of quantitative analysis, being higher for the parameter final pressure than for change in pressure. The $\mathrm{F}$ test was used initially to assess

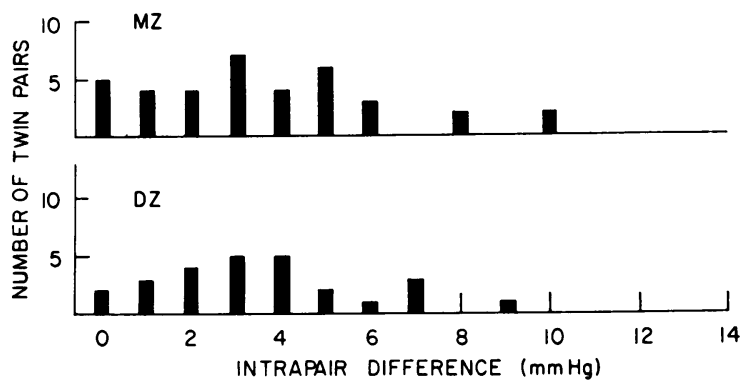

FIG. 1. Frequency distributions of intrapair difference for change in pressure among 26 dizygotic and 37 monozygotic twin pairs.

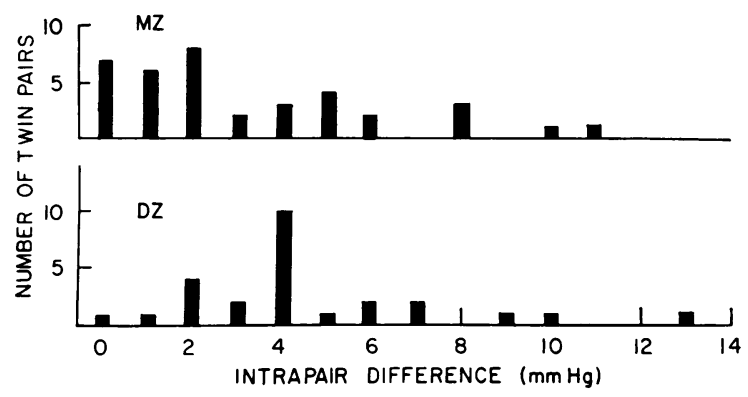

FIG. 2. Frequency distributions of intrapair difference for final pressure among 26 dizygotic and 37 monozygotic twin pairs. whether the variances of the distributions of intrapair difference for the $\mathrm{MZ}$ and $\mathrm{DZ}$ populations were significantly different. Frequency distributions of intrapair difference for change in pressure and final pressure are shown in Figs. 1 and 2. Differences in intrapair variance between the $M Z$ and $D Z$ populations were not significant $(p=0.37$ for change in pressure and $\mathrm{p}=0.12$ for final pressure).*

The size of the present study population was chosen so as to detect expected high values of $\mathrm{HI}$. In view of the negative nature of the findings, it is appropriate to examine the likelihood of failure to detect differences of various sizes between the $\mathbf{M Z}$ and $\mathrm{DZ}$ populations if in fact a difference did exist. For this purpose, the power of the $F$ test to detect significant differences in intrapair variance $(M Z$ vs DZ) was examined. In Fig. 3, the power of the F test to detect significant differences at the 0.05 level is given as a function of different values of $\mathrm{HI}$ when the numbers of $\mathrm{MZ}$ and $\mathrm{DZ}$ pairs are 37 and 26 respectively. It can be seen that the probability of rejecting the null hypothesis $\left(\sigma^{2} \mathrm{MZ}=\sigma^{2} \mathrm{DZ}\right.$, ie, $\mathrm{HI}=0$ ) based on the sample sizes in the present study, is 0.9 or more if the true heritability index is 0.67 or more.

Applicability of the F test is based on the assumption that the compared distributions are Gaussian. Departures from normality as shown for the frequency distributions in Figs. 1 and 2 were considered substantial enough to warrant the further application of a nonparametric test to determine whether the DZ pairs showed significantly greater intrapair differences than the $M Z$ pairs. For this purpose, the Wilcoxon 2-sample test (Noether, 1967) was

* The distributions shown in Fig. 1 represent the data when treated as shown in row 1 of Table V. When the data are treated so as to give maximum $\mathrm{HI}$ as in row 4 of Table $\mathrm{V}$, the difference in intrapair variance for final pressure is of borderline significance $(p=0.057)$. 


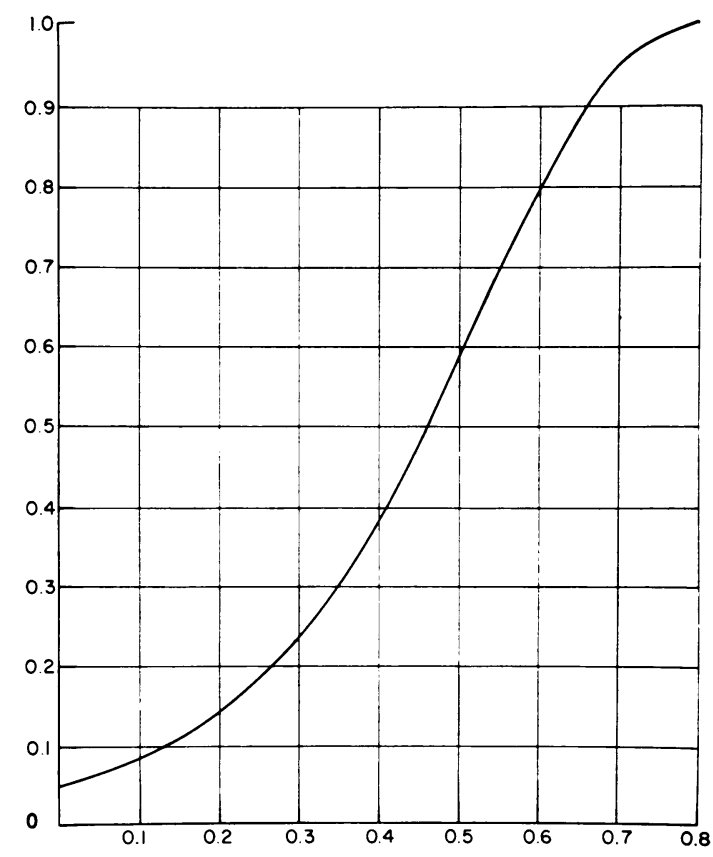

FIG. 3. Power of the F test (ordinate) $v$ s heritability index (abscissa) (ie, probability of rejecting the null hypothesis of the heritability index, $\mathrm{HI}=0$ when the alternative hypothesis that $\mathrm{HI}=$ value specified is true). Given: number of $\mathrm{DZ}$ pairs $=26$, number of $\mathrm{MZ}$ pairs $=37, \alpha=0.05$. $\mathrm{HI}=1-\sigma^{2} \mathrm{MZ} / \sigma^{2} \mathrm{DZ}$.

employed, giving for change in pressure $p=0.50$ (compared to $p=0.37$ as previously determined) and for final pressure, $p=0.02$ (compared to previously determined $p=0 \cdot 12$ ). For the parameter final pressure it is seen that the 2 tests of significance lead to different results. Thus, by some test methods we can demonstrate statistical significance for the relatively low levels of genetic influence as observed for final pressure. Indications of genetic influence for change in pressure, however, are lacking in these data.

\section{Discussion}

Published clinical observations which have been presented in support of monogenic inheritance of the steroid response imply both a high level of precision and reproducibility for the methods of phenotypic classification and a high level of gene penetrance. If these conditions prevail, and if the steroid response is inherited as postulated, then virtually complete concordance is expected among $M Z$ twinships. Values of HI should approach unity. Observed agreement among $M Z$ twins and observed values of $\mathrm{HI}$ are contrary to these expectations.

Results of this study fail to support a strongly dominant role of inheritance in determining variability of the hypertensive steroid response and suggest a major contribution of non-genetic factors. Caution is necessary in applying these observations. Since the present twin study was designed to reexamine an existing hypothesis, the method of topical steroid provocation and parameters of response were selected to agree with those upon which the hypothesis was founded, recognizing the problems inherent in the use of topically applied corticosteroid as a pharmacogenetic agent (B. Schwartz, 1966). It may be inappropriate to generalize the present findings to the condition of systemically administered steroids or to other parameters of responsiveness. Potential sources of error relating to zygosity assignment, clinical observation, or an unusual study sample must also be acknowledged with regard to the results of a single clinical investigation. It seems evident, however, that a theory of simple monogenic inheritance can be questioned on the basis of these new findings and there is need for further investigation of the determinants of the ocular hypertensive steroid response.

\section{Summary and Conclusions}

A twin study was undertaken to re-evaluate a widely held monogenic hypothesis relating to the ocular hypertensive steroid response. Low estimates of heritability were found which fail to support a strongly dominant role of inheritance in determining the described parameters of steroid response. Results of the study suggest that non-genetic factors play a major role in determining variation in the ocular response to a 4-week course of topical $0.1 \%$ dexamethasone. This new finding marks the need for further investigation of the determinants of this clinically important phenomenon.

We would like to acknowledge the help of Dr Gordon Allen, Laboratory of Socioenvironmental Studies, NIMH, who provided consultation on genetics; $\operatorname{Dr} M$. F. Armaly, George Washington University, Washington, DC, and Dr B. Becker, Washington University, St Louis, Missouri, who provided consultation on clinical procedure. $\mathrm{Mr}$ C. Webster Leyshon, Human Genetics Branch, NIDR, performed the blood serotyping.

A portion of the volunteer twin population was recruited through the cooperation of the National Academy of Sciences-National Research Council Twin Panel, Washington, DC.

\section{REFERENCES}

Armaly, M. F. (1965). Statistical attributes of the steroid hypertensive response in the clinically normal eye. I. The demonstration of three levels of response. Investigative Ophthalmology, 4, 187-197.

Armaly, M. F. (1966). The heritable nature of dexamethasoneinduced ocular hypertension. Archives of Ophthalmology, 75, 32-35. 
Armaly, M. F. (1967). Topical dexamethasone and intraocular pressure. In Glaucoma, pp. 73-96, a Symposium held at Tutzing Castle, 1966. Karger, Basel and New York.

Armaly, M. F. and Becker, B. (1965). Intraocular pressure response to topical corticosteroids. Federation Proceedings, 24, 1274-1278.

Becker, B. (1965). Intraocular pressure response to topical corticosteroids. Investigative Ophthalmology, 4, 198-205.

Becker, B. (1967). Current Concepts in Ophthalmology, chapter 9, pp. 132-147. C.V. Mosby, St Louis.

Becker, B. (1969). Glaucoma: recent endocrine studies. Acta Societatis Ophthalmologicae faponicae, 73, 2614-2619.

Becker, B. (1971). The genetic problem of chronic simple glaucoma. Annals of Ophthalmology, 3, 351-354.

Becker, B., Bresnick, G., Chevrette, L., Kolker, A. E., Oaks, M. C., and Cibis, A. (1966). The intraocular pressure and its response to topical corticosteroids in diabetes. Archives of Ophthalmology, 76, 477-483.

Becker, B. and Hahn, K. A. (1964). Topical corticosteroids and heredity in primary open-angle glaucoma. American fournal of Ophthalmology, 57, 543-551.

Becker, B. and Kolker, A. E. (1966). Topical corticosteroid testing in conditions related to glaucoma. In Corticosteroids and the Eye, edited by B. Schwartz. (International Ophthalmology Clinics, vol. 6, pp. 1005-1015.) Little Brown, Boston.

Becker, B. and Kolker, A. E. (1969). The corticosteroid intraocular pressure response. Thyroid function and phenylthiourea taste test. Documenta Ophthalmologica, 26, 313-317.

Clark, P. J. (1956). The heritability of certain anthropometric characters as ascertained from measurements of twins. American fournal of Human Genetics, 8, 49-54.

François, J. (1954). Cortisone et tension oculaire. Annales d'Oculistique, 187, 805-816.

François, J., Heintz-De Bree, C., and Tripathi, R. C. (1966). The cortisone test and the heredity of primary open-angle glaucoma. American fournal of Ophthalmology, 62, 844-852.

Holzinger, K. J. (1929). The relative effect of nature and nurture influences on twin differences. Fournal of Educational Psychology, 20, 241-248. Cited by: Osborne, R. H., and De George, F. V. (1959). In Genetic Basis of Morphological Variation. Published for the Commonwealth Fund of Harvard University Press, Cambridge, Mass.

Levene, R., Wigdor, A., Edelstein, A., and Baum, J. (1967). Topical corticosteroid in normal patients and glaucoma suspects. Archives of Ophthalmology, 77, 593-597.

Noether, G. E. (1967). Wilcoxon confidence intervals for location parameters in the discrete case. Fournal of the American Statistical Association, 62, 184-188.

Penrose, L. S. (1949). The Biology of Mental Defect. Sidgwick and Jackson, London.

Podos, S. M., Becker, B., and Morton, W. R. (1966). High myopia and primary open-angle glaucoma. American fournal of Ophthalmology, 62, 1039-1043.

Reuling, F. H. and Schwartz, J. T. (1970). Heritability of the effect of corticosteroids on intraocular pressure. Acta Geneticae Medicae et Gemellologiae, 19, 264-267.

Schwartz, B. (1966). The response of ocular pressure to corticosteroids. In Corticosteroids and the Eye, edited by B. Schwartz. (International Ophthalmology Clinics, vol. 6, pp. 929-989.) Little Brown, Boston.

Schwartz, J. T. (1970). A twin register for eye studies and need for collaboration. Acta Geneticae Medicae et Gemellologiae, 19, 344348.

Spaeth, G. L. (1966). Effects of topical dexamethasone on intraocular pressure and the water drinking test. Archives of Ophthalmology, 76, 772-783.

Spaeth, G. L. (1967). Traumatic hyphema, angle recession, dexamethasone hypertension and glaucoma. Archives of Ophthalmology, 78, 714-721. 